Submitted to:

Molecular Phylogenetics and Evolution

Revised version: July 18th, 2005

\title{
Genetic diversity and historical demography of Atlantic \\ bigeye tuna (Thunnus obesus)
}

\author{
Pilar Martíneza, ${ }^{a, b}$ Elena G. González ${ }^{a}$, Rita Castilhoc and Rafael Zardoyaa, ${ }^{a}$ \\ aDepartamento de Biodiversidad y Biología Evolutiva, Museo Nacional de Ciencias \\ Naturales, CSIC, José Gutiérrez Abascal, 2; 28006 Madrid, Spain \\ ๖Present address: Instituto Nacional de Toxicología, Luis Cabrera, 9; 28002 Madrid, Spain \\ ${ }^{\circ}$ CCMAR, Campus de Gambelas, University of Algarve, 8005-139 Faro, Portugal.
}

${ }^{*}$ Corresponding author:

Rafael Zardoya

Museo Nacional de Ciencias Naturales, CSIC

José Gutiérrez Abascal, 2

28006 Madrid

Spain

Tel: +34-91-4111328 ext 1129

Fax: +34-91-5645078

Email: rafaz@mncn.csic.es 


\section{Abstract}

Bigeye (Thunnus obesus) is a large, pelagic, and migratory species of tuna that inhabits tropical and temperate marine waters worldwide. Previous studies based on mitochondrial RFLP data have shown that bigeye tunas from the Atlantic Ocean are the most interesting from a genetic point of view. Two highly divergent mitochondrial haplotype clades (I and II) coexist in the Atlantic Ocean. One is almost exclusive of the Atlantic Ocean whereas the other is also found in the Indo-Pacific Ocean. Bigeye tuna from the Atlantic Ocean is currently managed as a single stock, although this assumption remains untested at the genetic level. Therefore, genetic diversity was determined at the mitochondrial control region to test the null hypothesis of no population structure in bigeye tuna from the Atlantic Ocean. A total of 331 specimens were sampled from four locations in the Atlantic Ocean (Canada, Azores, Canary Islands, and Gulf of Guinea), and one in the Indian and Pacific Oceans, respectively. The reconstructed neighbor-joining phylogeny confirmed the presence of Clade I and Clade II throughout the Atlantic Ocean. No apparent latitudinal gradient of the proportions of both clades in the different collection sites was observed. Hierarchical AMOVA tests and pairwise $\Phi_{S T}$ comparisons involving Atlantic Ocean Clade I and Clade II were consistent with a single stock of bigeye tuna in the Atlantic Ocean. Population genetic analyses considering phylogroups independently supported gene flow within Clade II throughout the Atlantic Ocean, and within Clade I between Atlantic and Indo-Pacific Oceans. The latter result suggests present unidirectional gene flow from the Indo-Pacific into the Atlantic Ocean. Moreover, mismatch analyses dated divergence of Clade I and Clade II during the Pleistocene, as previously proposed. In addition, migration rates were estimated using coalescent methods, and showed a net migration from Atlantic Ocean feeding grounds towards the Gulf of Guinea, the best-known spawning ground of Atlantic bigeye tuna.

Running title: Genetic diversity of Atlantic bigeye tuna

Key words: population genetics, mitochondrial control region, bigeye tuna, demography. 


\section{Introduction}

The great capability for long distance migration, the cosmopolitan geographic distribution, and the large effective population sizes of predatory pelagic marine fishes, together with the apparent absence of physical barriers to dispersal in the ocean predict panmixia (e.g. Palumbi, 1994). Yet, recent phylogeographic studies on scombroids and other highly migrating marine fishes (Buonnacorsi et al., 2001; Graves and McDowell, 2003; Carlsson et al., 2004; Castillo et al., 2004; Viñas et al., 2004a; Viñas et al., 2004b; Alvarado Bremer et al., 2005) convincingly show the existence of genetic structure. In some cases, present-day differences in ecology, behavior, and self recruitment seem to be the mechanisms underlying genetic differentiation (Reeb et al., 2000; Carlsson et al., 2004; Castillo et al., 2004; Viñas et al., 2004b; Zardoya et al., 2004) whereas in others, significant genetic divergences in mitochondrial sequence data are apparently related with vicariance associated to Pleistocene glacial cycles (Finnerty and Block, 1992; Graves and McDowell, 1995; Alvarado Bremer et al., 1996; Alvarado Bremer et al., 1998; Chow et al., 2000; Buonnacorsi et al., 2001; Graves and McDowell, 2003; Lecomte et al., 2004; Viñas et al., 2004a; Alvarado Bremer et al., 2005). Detecting genetic structure is crucial to establish appropriate fishery management stocks, and recent advances in population genetic (Excoffier et al., 1992) and historical demographic analyses (Slatkin and Hudson, 1991; Rogers and Harpending, 1992; Fu, 1997) can be very helpful in providing valuable and complementary information to catch and age composition data (Pauly et al., 2002).

Bigeye (Thunnus obesus Lowe, 1839) is a large, pelagic, and predatory tuna species inhabiting tropical and temperate waters between $50^{\circ} \mathrm{N}$ and $45^{\circ} \mathrm{S}$ (except in the Mediterranean). Bigeye tunas spawn exclusively around $15^{\circ} \mathrm{N}-15^{\circ} \mathrm{S}$ (Collette and Nauen, 1983), and the Gulf of Guinea in the Atlantic Ocean is their best-known 
breeding and nursery area (Alvarado Bremer et al., 1998). Young bigeye tunas (smaller than $70-80 \mathrm{~cm}$ ) tend to school with small yellowfin and skipjack tunas in shallow warm equatorial waters (Fonteneau et al., 2005). Catch and tagging data indicate that juveniles, as they grow, migrate into Northern and Southern Atlantic Ocean temperate feeding grounds (Fonteneau et al., 2005). Mature adults (around $110 \mathrm{~cm}$; Pereira, 1987) of bigeye tuna live in deep cold waters, and migrate back to the Gulf of Guinea during the spawning season. Although tagging data from the eastern Pacific Ocean indicate regional fidelity for bigeye tuna (Schaefer and Fuller, 2005), it is still elusive whether adults after spawning in the Gulf of Guinea may show philopatric behavior.

Bigeye is currently considered the most valuable species of tuna due to the large number of individuals $(300,000$ tons per year) that are sold at high prices (over $\$ 10 / \mathrm{kg}$ ) on the Japanese sashimi market (Fonteneau et al., 2005). Until the early1990s bigeye tunas were moderately fished (Fonteneau et al., 2005), but a rapid increase of total annual catches has since been recorded, and there are serious concerns that the species may be overexploited worldwide (Fonteneau et al., 2005). Bigeye tunas from the Atlantic, Pacific, and Indian Oceans are each considered single stocks, and they are managed independently by three main international commissions, the ICCAT (International Commission for the Conservation of Atlantic Tuna), the IATTC (Inter-American Tropical Tuna Commission), and the IOTC (Indian Ocean Tuna Commission), respectively. In agreement with this policy, population genetic studies based on restriction fragment length polymorphism (RFLP) analyses of the mitochondrial ATCO (ATPase6-COIII) region, and on microsatellites revealed no internal structuring within the Pacific (Grewe and Hampton, 1998) and Indian (Appleyard et al., 2002) Oceans, respectively. Thus far, however, the null hypothesis of a single stock within the Atlantic Ocean remains untested (Alvarado 
Bremer et al., 1998). Yet, up to three different regions (North, Central, and South) are often defined in stock assessment studies of bigeye tuna in the Atlantic Ocean (Miyabe et al., 2005).

Phylogenetic analysis of mitochondrial DNA control region supported the existence of two groups, Clade I that occurred both in the Atlantic and Indo-Pacific Oceans, and Clade II that was mainly restricted to the Atlantic Ocean (Alvarado Bremer et al., 1998). The presence of these two clades was further confirmed based on RFLP analyses of different mitochondrial gene fragments, (Chow et al., 2000) and a barrier to gene flow around South Africa was proposed (Alvarado Bremer et al., 1998; Chow et al., 2000). During glacial maxima, seasonal migration of bigeye tunas across the Cape of Good Hope was likely interrupted, and secondary contact was later re-established in the inter-glacial period (Finnerty and Block, 1992; Graves and McDowell, 1995; Alvarado Bremer et al., 1998; Chow et al., 2000; Buonnacorsi et al., 2001). Yet, it is not well-established whether there is a present lack of gene flow between the Atlantic and Indo-Pacific Oceans (Chow et al., 2000) or some unidirectional gene flow from the Indo-Pacific Ocean into the Atlantic Ocean (Alvarado Bremer et al., 1998; Buonnacorsi et al., 2001). These competing hypotheses need to be tested using appropriate population genetic statistics (i.e AMOVA, $\Phi_{S T}$, coalescence methods).

We examined genetic variability of bigeye tuna in the Atlantic Ocean using mitochondrial control region sequence data because this marker has been shown to be particularly sensitive in detecting population genetic structure of marine migrating and predatory fish (Buonnacorsi et al., 2001). Phylogenetic analyses and statistical comparisons among four Atlantic Ocean samplings along a geographic cline were used 1) to confirm the existence of two different mitochondrial clades throughout the Atlantic Ocean, 2) to determine whether the two mitochondrial clades show any 
distinct phylogeographical structuring, and 3) to test the null hypothesis of a single stock of bigeye tuna in the Atlantic Ocean. In addition, different year replicate collections in two of the Atlantic Ocean sites were used to test temporal stability of haplotype frequencies (Buonnacorsi et al., 2001). Moreover, one population from the Indian Ocean and one from the Pacific Ocean were analyzed to discern among competing hypotheses regarding present gene flow between Atlantic and Indo-Pacific

Oceans. In particular, the null hypothesis of homogeneity of Clade I across oceans was tested using appropriate population genetic statistics. Finally, historical demographic analyses were performed to test the hypothesis that Pleistocene glacial cycles had a major influence in the origin of Clades I and II.

\section{Materials and Methods}

\section{Sampling}

Determining population genetic structure of marine large pelagic scombroid fish species is particularly challenging because sampling strategy needs to take into account their wide distribution, large population sizes, migratory behaviour, and high capacity of dispersal (Carlsson et al., 2004; Viñas et al., 2004b; Zardoya et al., 2004). Our study was centered in the Atlantic Ocean, and localities were chosen to ensure a thorough geographical coverage (unfortunately we were not able to obtain samples from the Southern temperate feeding grounds). ICCAT arranged collection of Atlantic bigeye tuna samples from Gulf of Guinea, Canary Islands, Azores and Canada during 2001. A second sampling was performed during 2003 in the Gulf of Guinea and the Canary islands in order to test temporal stability of inferred population genetic diversity. IATTC and a commercial fishing operator provided us with samples from the Pacific and Indian Oceans, respectively. The number (average of 41 ) and sizes of the fish collected per site are listed in Table 1. Both adult and 
juvenile classes can be found at the Gulf of Guinea. Our collections included exclusively juveniles (Table 1). Moreover, size composition of temporal replicates was homogeneous. Samples were stored either in absolute ethanol or frozen at $-20^{\circ} \mathrm{C}$.

DNA extraction, PCR amplification, and automated sequencing

Total DNA was isolated from muscle tissue. Each sample was homogenized overnight at $55^{\circ} \mathrm{C}$ in extraction buffer (EDTA $0.1 \mathrm{M}$, Tris-HCl pH $8.00 .05 \mathrm{M}$, SDS $1 \%$, and Proteinase $\mathrm{K} 0.2 \mathrm{mg} / \mathrm{ml}$ ), and DNA was purified using a standard phenol/chloroform extraction followed by an ethanol precipitation. PCR amplification of the 5'-end of the mitochondrial control region (D-loop) was achieved using the following profile: a single cycle of $5 \mathrm{~min}$ at $94^{\circ} \mathrm{C}$, followed by 35 cycles of $1 \mathrm{~min}$ at $94^{\circ} \mathrm{C}, 1 \mathrm{~min}$ at $50^{\circ} \mathrm{C}$, and $1 \mathrm{~min}$ at $72^{\circ} \mathrm{C}$, with a final cycle of $5 \mathrm{~min}$ at $72{ }^{\circ} \mathrm{C}$. PCR primers were L-Pro1 5'-ACTCTCACCCCTAGCTCCCAAG-3' and H-DL 1 5'CCTGAAGTAGGAACCAGATGCCAG-3' (Ostellari et al., 1996). PCR products were purified by ethanol precipitation, and sequenced using the primer L-Pro 1 and the BygDye Terminator Sequencing Ready Reaction v3.0 kit (Applied Biosystems) following manufacturer's instructions in an $A B I 3700$ automated sequencer. The new sequences were deposited in Genbank under the accession numbers DQ126342DQ126676.

Phylogenetic, population genetic, and demographic analyses

Alignment of nucleotide sequences was performed using Clustal X v1.83 (Thompson et al., 1997), and further revised by eye. Gaps resulting from the alignment were excluded from phylogenetic analyses. The data set was subjected to the neighbour-joining (NJ) method (Saitou and Nei, 1987) of phylogenetic inference. 
NJ analyses were carried out with PAUP v4.0b10 (Swofford, 1998). The Akaike information criterion (AIC) implemented in Modeltest v3.6 (Posada and Crandall, 1998) was used to select the evolutionary models that best fit the empirical data sets. The inferred evolutionary model and parameters were used to estimate maximum likelihood distances. Robustness of the resulting tree was tested with bootstrapping (Felsenstein, 1985).

Control region haplotypes AAA1 and BAB from the Indo-Pacific Ocean, and BBB2 from the Atlantic Ocean were employed as representatives of the clades observed by Alvarado Bremer et al. (1998). Two mitochondrial control region sequences of bigeye tuna found in Genbank (AF095705-06) were also included in the phylogenetic analyses. Homologous sequences of T. thynnus (Alvarado Bremer et al., 1998; AF390405), of T. maccoyii (Alvarado Bremer et al., 1998), and of T. albacares (AF301203) were used as outgroups.

Population genetic analyses were performed using Arlequin 2001 (Schneider et al., 2000) and DnaSP 4.0 (Rozas et al., 2003) based on mitochondrial control region sequence data. Descriptive statistics such as the number of polymorphic sites $(S)$, haplotype diversity $\left(H_{d} ;\right.$; Nei, 1987$)$, nucleotide diversity $(\pi ; \mathrm{Nei}, 1987)$ and the average number of pairwise nucleotide differences ( $k$; Tajima, 1983) were determined for each geographic population. The inter-haplotype levels of divergence were estimated using the fixation index $\Phi_{\mathrm{ST}}$ (Excoffier et al., 1992), which includes information on mitochondrial haplotype frequency (Weir and Cockerham, 1984), and genetic distances (Tamura-Nei; Tamura and Nei, 1993 with gamma correction; TrN93). Significance of pairwise population comparisons was tested by 20,000 permutations. An analysis of molecular variance (AMOVA) was used to examine the amount of genetic variability partitioned within and among populations (Excoffier et al., 1992). AMOVA tests were organized in a hierarchical manner so that population 
structure was studied at increments of increasing spatial scale, which range from structure within and among different populations to an entire metapopulation concept. Permutation procedures $(\mathrm{N}=20,000)$ were used to construct null distributions, and test the significance of variance components for each hierarchical comparison (Guo and Thompson, 1992). In all instances with multiple tests, $p$-values were adjusted using the sequential Bonferroni correction (Rice, 1989). The nearestneighbour $S_{\text {nn }}$ statistic (Hudson, 2000) was estimated using DnaSP 4.0 (Rozas et al., 2003). This statistic measures population differentiation by testing whether low divergent sequences are from the same location, and it is particularly useful when populations show high levels of haplotype diversity.

The entire mitochondrial control region data set and the two phylogroups (Clades I and II) revealed from the phylogenetic analysis were tested against constant population size and sudden population expansion models using the mismatch distribution (Slatkin and Hudson, 1991; Rogers and Harpending, 1992; Schneider and Excoffier, 1999) as implemented in Arlequin 2001 (Schneider et al., 2000) and DnaSP 4.0 (Rozas et al., 2003). This analysis compares the distribution of the frequency of pairs of individuals who differ by a certain number of nucleotide differences. The pattern of pairwise differences between haplotypes usually forms a unimodal wave in samples from expanding populations, whereas samples drawn from populations at demographic equilibrium yield a multimodal pattern of numerous sharp peaks (Slatkin and Hudson, 1991; Rogers and Harpending, 1992; Schneider and Excoffier, 1999). The validity of the assumed stepwise expansion model was tested with a parametric bootstrapping approach (1000 permutations). Deviations from the sudden population expansion model were further tested using the Harpending's raggedness index (Hri; Harpending, 1994). To test for deviations from neutrality (as would be expected under population expansion) we used Tajima's D (Tajima, 1989) 
and Fu's Fs (Fu, 1997) tests as implemented in NeutralityTest v1.1 (Fu, 1997) and DnaSP 4.0 (Rozas et al., 2003), respectively. Recently, Ramos-Onsins and Rozas (2002) showed that Fu's Fs test outperforms other tests in detecting population growth for large sample sizes.

In addition, we used coalescence-based Markov-Chain Monte Carlo (MCMC) methods implemented in Migrate v1.7.3 (Beerli and Felsenstein, 1999; Beerli, 2002) to estimate the products of effective female population size and mutation rate $\left(N_{e(f)}\right.$ $\mu$ ), and effective female population size and migration rate $\left(N_{e(f)} m\right)$ based on mitochondrial control region sequence data. $F_{S T}$ estimates of effective population sizes and migration rates were used as initial values. A MCMC run consisted of ten short and three long chains with 10.000 and 100.000 genealogies, respectively, and after discarding the first 10000 genealogies (burn-in). One of every 100 reconstructed genealogies was sampled. The run was repeated five times to verify consistency of results, and estimates are the average of the five runs.

\section{Results}

\section{Genetic variation}

Genetic analyses were conducted on 335 individuals (Table 1). Four individuals initially identified as bigeye tuna where found to be yellowfin tuna because their sequences grouped with those of Thunnus albacares in the phylogenetic analyses (see below). Presence of both species within single captures is rather frequent because they share ecology (particularly when they are young) and distribution ranges (Miyabe and Bayliff, 1998). These samples were excluded from further analyses. 
Mitochondrial control region sequence data of 258 individuals (Guinea, Azores, Canary, Canada, Indian, and Pacific) produced an initial alignment of 397 bp, which was reduced to 338 positions after gap exclusion. A total of 118 sites were polymorphic, 26 were singleton variable sites, and 92 were parsimony-informative. Polymorphic sites defined a total of 222 different haplotypes. Overall haplotype diversity was high (0.999). A total of 194 haplotypes were unique, and the most abundant haplotype was found in four specimens (one from each Atlantic Ocean population). The overall nucleotide diversity, and the average number of pairwise nucleotide differences were 0.054 and 18.17 , respectively. Population genetic statistics are listed in Table 1.

\section{Phylogenetic relationships}

The Akaike information criterion selected $G T R+I+\Gamma$ (empirical base frequencies: $A=$ $0.38, C=0.18, G=0.15, T=0.29$; substitution rates: $A-C=3.69, A-G=61.93, A-T=$ 1.90, $\mathrm{C}-\mathrm{G}=4.00, \mathrm{C}-\mathrm{T}: 94.52, \mathrm{G}-\mathrm{T}=1.00$; proportion of invariable sites $=0.55 ; \alpha=$ 0.59) as the evolutionary model that best fit the mitochondrial control region sequence data set. The reconstructed NJ phylogeny (using maximum likelihood distances) of bigeye tuna is shown in Figure 1. Most bigeye tuna haplotypes are grouped into two highly divergent clades, which correspond to clades I and II of Alvarado Bremer et al. (1998). Clade I included individuals from all analyzed oceans whereas clade II was restricted exclusively to the Atlantic Ocean, and comprided $70 \%$ of Atlantic individuals (Fig. 1). The latter clade showed a high statistical support (89\% bootstrap value). Within each clade, phylogenetic relationships lacked bootstrap support, and no apparent relationship between haplotypes from the same geographic area was detected. In all collections (but particularly in the Indian and Pacific Ocean samples), several individuals (including BAB from Alvarado Bremer et 
al., 1998) could not be confidently recovered within Clade I or Clade II. The proportions in the different collection sites of Clades I and II are shown in Figure 2. No apparent latitudinal gradient of the proportion of clades is observed in the Atlantic Ocean. Population genetic statistics of each clade are very similar (Table 2). Mean pairwise uncorrected $p$ distances between bigeye tuna, and outgroups and yellowfin tuna are $0.11 \pm 0.01$ and $0.09 \pm 0.01$, respectively. Mean pairwise uncorrected $p$ distance between Clade I and Clade II is $0.07 \pm 0.01$. Both withinclades mean pairwise uncorrected $p$ distance is $0.03 \pm 0.01$.

\section{Population structuring}

The best-fit evolutionary model is not implemented in Arlequin 2000. Therefore, we used the second best fit model i.e. TrN (Tamura and Nei, 1993) $+\Gamma$ to perform AMOVA tests and to estimate $\Phi_{S T}$ values. Hierarchical AMOVA tests showed overall significant levels of genetic structuring $\left(\Phi_{S T}=0.22 ; p<0.01\right)$ among bigeye tuna collections (Table 3 ). An overall significant structure was detected for Clade I ( $\Phi_{S T}$ $=0.02 ; p=0.01)$ but no structure was revealed for Clade II $\left(\Phi_{S T}=-0.05 ; p=0.72\right)$

(Table 3). A two gene pool structure separating Atlantic versus Indian and Pacific Ocean samples using only individuals belonging to Clade I was not significant ( $\Phi_{C T}=-$ $0.01 ; p=0.40)$ (Table 3).

Pairwise $\Phi_{S T}$ comparisons of Guinea 1 and Guinea 2 as well as Canary 1 and Canary2 populations were not significant (not shown). Hence, genetic variation in the same location was found to be stable through time given that size (age) composition of the samples was homogeneous in the temporal replicates. Only $\Phi_{S T}$ comparisons involving any Atlantic Ocean population, and either the Indian or the Pacific Ocean populations were statistically significant (Table 4). Interestingly, only pairwise $\Phi_{S T}$ comparisons of Clade I between Guinea and the Indian or Pacific Ocean 
populations showed significant values when the analyses were performed considering phylogroups independently (Table 5). Genetic differentiation among populations was further tested using the nearest-neighbour statistic. The test was significant $(p<0.05)$ for the entire set $\left(S_{n n}=0.265\right)$ but not for Clade I $\left(S_{n n}=0.320\right)$ and Clade II $\left(S_{\mathrm{nn}}=0.209\right)$.

\section{Demographic patterns}

The parameters of the expansion model and the Harpending's raggedness indexes for the entire mitochondrial control region data set, and the phylogroups are shown in Table 6. The mismatch distribution including both clades was bimodal (Figure 3), with one mode corresponding to the number of differences within the clades, and the other to differences between the two clades. The separate analysis of Clade I and Clade II yielded in both cases a unimodal distribution, not significantly different (as measure by the sum of squared deviation; $p>0.05$ ) from that predicted by the growth expansion model. The Harpending's raggedness indexes were low indicating a significant fit of the observed and expected distributions, and therefore further evidence of population expansion (Harpending, 1994). The mismatch analyses allowed the estimation of effective female population size, and time and rate of expansion (Harpending, 1994). Estimated effective female population size after expansion $\left(\theta_{1}\right)$ was about 3700 and 50 times higher than before expansion $\left(\theta_{0}\right)$ for Clade I and Clade II, respectively. Estimated $\tau$-values were very similar and had overlapping 95\% confidence intervals (not shown) indicating that population expansion in both clades may date back to about the same historical period. Reported mutation rates for the mitochondrial region may vary between $1.1 \times 10^{-7}$ (McMillan and Palumbi, 1997) and $3.6 \times 10^{-8}$ (Donaldson and Wilson, 1999) per site per year. Bigeye tuna mature during their third year of life (Calkins, 1980). Hence, 
the estimated times since population growth for Clade I and Clade II are 0.43-1.33 x $10^{6}$ and $0.32-1.00 \times 10^{6}$ years before present, respectively. Additionally, Fu's $F_{\mathrm{s}}$ statistic indicated a significant deviation from neutrality (excess of low-frequency haplotypes) in Clade I and Clade II, as may be expected when a population is under selection or expanding. The more conservative Tajima's test indicated significant deviation from neutrality only for Clade I.

Coalescence methods were applied to the entire mitochondrial control region data set in order to infer migration rates and effective female population sizes (Table 7). All populations showed similar female population sizes (as inferred from theta values in Table 7) between $0.5-5.8 \times 10^{6}$ individuals. There is little migration between the Atlantic and Indo-Pacific Oceans. Within the Atlantic Ocean, migrants move from the different populations towards the Gulf Guinea. High levels of migration are detected between the Indian and Pacific Oceans. Coalescence theory requires large sampling sizes in order to obtain an accurate estimate of migration rates and effective populations sizes. Hence, no analyses were performed based on Clade I and Clade II, independently.

\section{Discussion}

Several recent studies focused on tunas and related scombroid species (Jackson et al., 2001; Carlsson et al., 2004; Viñas et al., 2004a; Viñas et al., 2004b; Alvarado Bremer et al., 2005) reveal that large marine pelagic fishes show significant genetic structuring, which may eventually accelerate collapse of stocks if not properly taken into account by fishery management policies. Atlantic bigeye tuna is managed as a single stock (Alvarado Bremer et al., 1998). Given the migratory behavior of this species, however, up to three regions are tentatively considered in stock assessment 
studies (Miyabe et al., 2005), and the existence of genetic structure within the Atlantic Ocean still needs to be tested. Following previous evidence that suggested inter-oceanic genetic differentiation among bigeye tuna populations, and the existence of a clade restricted to the Atlantic Ocean (Alvarado Bremer et al., 1998), we performed a comprehensive survey of bigeye tuna in northern (Canada), central (Azores, Canary Islands), and southern Atlantic (Guinea) Ocean. One population from the eastern Indian Ocean and one from the western Pacific Ocean were also sampled. The new sequence data was analyzed with appropriate phylogenetic and population genetic methods, and taking into consideration the co-existence of two divergent mitochondrial clades in the Atlantic Ocean.

\section{Genetic structure of bigeye tuna within the Atlantic Ocean}

The nucleotide sequence of the 5'-end of the mitochondrial control region showed high levels of variation with about $20 \%$ segregating sites. Overall $(\pi=0.039$ $0.063)$ and per clade $(\pi=0.028-0.039)$ nucleotide diversities were within the range reported for other tuna species (Viñas et al., 2004a). Haplotypic diversity was also high with the majority of haplotypes sampled only once, a typical pattern of scombroid fish (e.g. Zardoya et al., 2004).

The recovered NJ phylogeny based on mitochondrial control region sequence data confirmed the existence of two mitochondrial clades (I and II) throughout the Atlantic Ocean as previously suggested (Alvarado Bremer et al., 1998; Chow et al., 2000; Appleyard et al., 2002) based mostly on RFLP data. Mitochondrial control region sequence divergence between Clade I and Clade II of bigeye tuna (7\%) is similar to that reported between clades for Atlantic bonito (8.1\%) (Viñas et al., 2004a). AMOVA tests and pairwise $\Phi_{S T}$ comparisons are consistent with a single stock of bigeye tuna in the Atlantic Ocean, given that the existence of two 
mitochondrial clades is considered. The null hypothesis of genetic homogeneity among Atlantic populations of bigeye tuna is supported both for Clade I and Clade II. Moreover, both clades do not show any phylogeographic structure within the Atlantic Ocean. Their proportion is homogeneous among northern, central, and southern Atlantic Ocean populations, as well as stable over time. However, coalescent inference of migration rates shows a net dispersal of individuals towards the Gulf of Guinea, which may likely be associated with spawning behavior. This result confirms tagging and catch data (Fonteneau et al., 2005). Hence, our results provide genetic support for the current fishery managing policy of the ICCAT for this species (Alvarado Bremer et al., 1998).

Phylogeography and historical demography of bigeye tuna across the Cape of Good Hope

Phylogenetic analyses based on the new mitochondrial control region sequence data confirm that Clade I is found in all oceans whereas Clade II is restricted to the Atlantic ocean (but see Appleyard et al., 2002) that reported a few individuals of Clade II in Madagascar and Seychelles). The presence of two highly divergent mitochondrial DNA lineages has been also described in Atlantic bonito (Viñas et al., 2004a), and several billfishes (Scombroidei: Xiphiidae) such as blue marlin (Buonnacorsi et al., 2001), sailfish (Graves and McDowell, 2003), and swordfish (Buonnacorsi et al., 2001; Graves and McDowell, 2003; Alvarado Bremer et al., 2005). The Atlantic bonito exhibits two sympatric clades in the Mediterranean Sea (Viñas et al., 2004a) whereas billfishes (Buonnacorsi et al., 2001; Graves and McDowell, 2003; Alvarado Bremer et al., 2005) and bigeye tuna (Alvarado Bremer et al., 1998; present study) have two sympatric clades in the Atlantic Ocean. The observed genetic mitochondrial discontinuities may have originated by common 
vicariant events resulting from a general lowering of the temperature of the water that produced reduction of tropical marine habitats, and isolation of populations during Pleistocene glacial maxima (Alvarado Bremer et al., 1998; Graves and McDowell, 2003; Viñas et al., 2004a; Alvarado Bremer et al., 2005). In the case of the Atlantic bonito, the Mediterranean population was likely isolated from the Atlantic Ocean whereas in billfishes and bigeye tuna gene flow was prevented around the Cape of Good Hope, separating Atlantic from Indo-Pacific populations. Secondary contact during inter-glacial periods by unidirectional gene flow of formerly allopatric populations would result in the contemporary asymmetrical distribution of the clades (Peeters et al., 2004; Alvarado Bremer et al., 2005).

The evidence of present dispersal (and thus, gene flow) across the Cape of Good Hope is elusive. Tagging data suggests that individuals of bigeye tuna from the Indian Ocean seasonally cross to the Atlantic Ocean using the Agulhas current, and later return back to the Indian Ocean (Chow et al., 2000; Alvarado Bremer et al., 2005). In agreement, AMOVA tests, pairwise $\Phi_{S T}$ comparisons, and the $S_{\mathrm{nn}}$ statistic reject the null hypothesis of a global panmictic population of bigeye tuna. However, genetic heterogeneity was not statistically significant when the analyses were performed taking into account phylogroups independently. Therefore, we can conclude that the genetic differentiation detected by population genetic analyses is due to phylogenetic signal rather than to absence of present gene flow. Moreover, our results are consistent with panmixia within Clade I. This result may imply contemporary unrestricted gene flow across the Cape of Good Hope for members of the ubiquitous clade, as similarly suggested for blue marlin (Buonnacorsi et al., 2001). According to our results, some of the specimens that reach the Atlantic Ocean coming from the Indian Ocean may not return allowing genetic continuity within Clade I. Alternatively, the Cape of Good Hope may be indeed an effective 
barrier to gene flow at present, and the observed genetic homogeneity of Clade I between oceans would indicate that there has not been enough time since the last glacial maximum (18-21,000 years ago) to allow genetic differentiation at the mitochondrial level. This latter hypothesis is, however, less likely because of the enhanced effect of genetic drift on mitochondrial DNA due to its lower effective population size (Buonnacorsi et al., 2001). On the other hand, the general absence of Clade II individuals in the Indo-Pacific (but see Appleyard et al., 2002) suggests that the boundary region between the Atlantic and Indian Oceans is an effective barrier at least for bigeye tuna Clade II specimens. The great effort of migrating against the Agulhas current (Peeters et al., 2004) and the cold Benguela upwelling (Buonnacorsi et al., 2001), and a putative stronger philopatric behavior to the spawning area in the Gulf of Guinea of Clade II individuals could account for this pattern. Indeed, coalescent analyses indicated a minimal migration trend between the Atlantic and the Indo-Pacific Oceans. Migration between the Indian and Pacific Oceans was estimated to be about two to three orders of magnitude higher than across the Cape of Good Hope.

Unimodal mismatch distributions, significant negative values of Fu's $F_{\mathrm{s}}$ and the low values of the Harpending's reggedness index for each clade support sudden population expansions after genetic isolation (Harpending, 1994; Fu, 1997). The dating of the expansions based on estimated $\tau$-values confirms the Pleistocene origin of both clades in connection with eustatic changes in sea level and lowering of the temperatures. Interestingly, mismatch analyses suggest that effective population growth was approximately 75 times higher for Clade I than for Clade II. This extremely different expansion rates may have also contributed to the asymmetrical distribution patterns of Clade I (inter-oceanic) and Clade II (restricted to the Atlantic Ocean). 
At present, fishery global management of bigeye tuna assumes, based on biological data (Pallares et al., 1998), that each ocean basin should be considered an independent management unit. The existence of significant genetic structure between the Atlantic Ocean and the Indo-Pacific Ocean (based on $\Phi_{\mathrm{st}}$ comparisons), as well as the lack of genetic differentiation found within the Atlantic (this paper), the Indian (Appleyard et al., 2002), and the Pacific (Grewe and Hampton, 1998) Oceans is consistent with such policy. However, bigeye tuna fishery managers currently neglect the existence of a mitochondrial phylogroup (namely Clade II) that is restricted to the Atlantic Ocean, and that occurs in sympatry with a more ubiquitous inter-oceanic clade (namely Clade I). Although, bigeye tuna abundance is above the biomass estimated for maximum sustainable yield $(100,000$ tons; Fonteneau et al., 2005), and Clade II is well represented and temporally stable in the different collection sites, it would be worthy to monitor the evolution in number of individuals of Clade II over the years. It will be also important to gather further biological data to determine whether Clade II individuals have differential spawning areas or recruitment. The loss of Clade II may not be in the near future a potential problem for bigeye tuna fisheries, but would certainly mean reducing the genetic diversity of the species, which could ultimately lead to a decrease in fitness and a reduction on adaptive capacity.

The presence of two co-occurring mitochondrial clades of bigeye tuna in the Atlantic Ocean needs to be contrasted with nuclear markers (e.g. microsatellites). Mitochondrial and nuclear evidence may be highly congruent (i.e. individuals within a clade mate selectively, and clades may represent two sympatric sibling species) or dissimilar (i.e. clades would represent ancient polymorphism). For instance, a recent study (Buonnacorsi et al., 2001) compared mitochondrial and nuclear patterns of Atlantic and Pacific blue marlins. The presence of a large cluster of alleles almost 
exclusively in Atlantic individuals at one microsatellite locus confirmed that mitochondrial clade distribution was the result of Pleistocene vicariance (Buonnacorsi et al., 2001), and that if gene flows occurs, it is likely to be unidirectional from the Pacific Ocean to the Atlantic Ocean. Interestingly, this study also showed that distinct $F_{\mathrm{ST}}$ distributions are expected from mitochondrial and nuclear markers due to differences in genetic drift, and mutation rate.

After this manuscript was submitted, Durand et al. (2005) reported a study of bigeye tuna centered on samples in the contact zone of Clades I and II off southern Africa, which used both mitochondrial and nuclear markers. Allele-frequency differences at one nuclear intronic locus and one microsatellite locus between Atlantic and Indo-Pacific collections seemed to confirm the vicariant origin of mitochondrial clades during the colder Pleistocene periods, and rejected the hypothesis that the two mitochondrial clades may represent two different species (Durand et al., 2005).

\section{Acknowledgements}

We thank ICCAT, IATTC, and OPAGAC (Organización de Productores de Grandes Atuneros Congeladores) for collecting samples. Guillermo Fisch (Bigeye tuna year program; BETYP) was in charge of sampling coordination. Two anonymous reviewers gave insightful comments on a previous version of the manuscript. EGG was supported by a MEC (Ministerio de Educación y Ciencia) predoctoral grant. This work received partial financial support from the BETYP-ICCAT and from a project of the MEC to RZ (REN2001-1514/GLO). 


\section{Figure Legends}

Figure 1. Neighbor-joining tree of bigeye tuna mitochondrial control region sequences reconstructed using GTR $+\mathrm{I}+\Gamma$ distances. The geographic origin of each haplotype is shown. Bootstrap values after 1000 replicates are shown above nodes.

Figure 2. Schematic map showing relative proportions of mitochondrial control region Clade I (white) and Clade II (black) for each population of $T$. obesus at the Atlantic (Canada, Azores, Canary Is. and Gulf of Guinea), the Indian, and the Pacific Oceans.

Figure 3. Observed, growth-decline model, and constant population model mismatch distributions for all pairwise combinations of: the entire mitochondrial control region data set, 258 individuals; Clade I, 107 individuals and Clade II, 124 individuals 


\section{References}

Alvarado Bremer, J.R., Mejuto J., Greig T.W., Ely B., 1996. Global population structure of the swordfish (Xiphias gladius L.) as revealed by analysis of the mitochondrial control region. J. Exp. Mar. Biol. Ecol. 197, 295-310.

Alvarado Bremer, J.R., Stequert B., Robertson N.W., Ely B., 1998. Genetic evidence for inter-oceanic subdivision of bigeye tuna (Thunnus obesus) populations. Mar. Biol. 132, 547-557.

Alvarado Bremer, J.R., Viñas J., Mejuto J., Ely B., Pla C., 2005. Comparative phylogeography of Atlantic bluefin tuna and swordfish: the combined effects of vicariance, secondary contact, introgression, nd population expansion on the regional phylogenies of two highly migratory pelagic fishes. Mol. Phylogenet. Evol. 36, 169-187.

Appleyard, S.A., Ward R.D., Grewe P.M., 2002. genetic stock structure of bigeye tuna in the Indian Ocean using mitochondrial DNA and microsatellites. J. Fish Biol. $60,767-770$.

Beerli, P., 2002. Migrate: documentation and program, part of Lamarc. Department of Genome Sciences, University of Washington, Seattle

Beerli, P., Felsenstein J., 1999. Maximum likelihood estimation of migration rates and effective population numbers in two populations using a coalescent approach. Genetics 152, 763-773.

Buonnacorsi, V.P., McDowell J.R., Graves J.E., 2001. Reconciling patterns of interocean molecular variance from four classes of molecular markers in blue marlin (Makaira nigricans). Mol. Ecol. 10, 1179-1196.

Calkins, T.P., 1980. Synopsis of biological data on the bigeye tuna (Thunnus obesus) (Lowe 1839) in the Pacific Ocean. IATTC Spec. Rep. 2, 213-260. 
Carlsson, J., McDowell J.R., Diaz-Jaimes P., Carlsson J.E., Boles S.B., Gold J.R., Graves J.E., 2004. Microsatellite and mitochondrial DNA analyses of Atlantic bluefin tuna (Thunnus thynnus thynnus) population structure in the Mediterranean Sea. Mol Ecol 13, 3345-56.

Castillo, A.G., Martinez J.L., Garcia-Vazquez E., 2004. Fine spatial structure of Atlantic hake (Merluccius merluccius) stocks revealed by variation at microsatellite loci. Mar Biotechnol (NY) 6, 299-306.

Chow, S., Okamoto H., Miyabe N., Hiramatsu K., Barut N., 2000. Genetic divergence between Atlantic and Indo-Pacific stocks of bigeye tuna (Thunnus obesus) and admixture around South Africa. Mol. Ecol. 9, 221-227.

Collette, B.B., Nauen C.E., 1983. FAO species catalogue. Vol. 2. Scombrids of the world. An annotated and illustrated catalogue of tunas, mackerels, bonitos and related species known to date. FAO Fish. Synop. 2(125). 137 p.,

Donaldson, K.A., Wilson R.R., 1999. Amphi-panamaic geminates of snook (PercoideiCentropomidae) provide a calibration of divergence rates in the mitochondrial DNA control region of fishes. Mol. Phylogenet. Evol. 13, 208-213.

Durand, J.D., Collet A., Chow S., Guinand B., Borsa P., 2005. Nuclear and mitochondrial DNA markers indicate unidirectional gene flow of Indo-Pacific to Atlantic bigeye tuna (Thunnus obesus) populations, and their admixture off southern Africa. Mar. Biol. 147, 313-322.

Excoffier, L., Smouse P.E., Quattro J.M., 1992. Analysis of molecular variance inferred from metric distances among DNA haplotypes: application to human mitochondrial DNA restriction data. Genetics 131, 479-491.

Felsenstein, J., 1985. Confidence limits on phylogenies: an approach using the bootstrap. Evolution 39, 783-791. 
Finnerty, J.R., Block B.A., 1992. Direct sequencing of mitochondrial DNA detects highly divergent haplotypes in blue marlin (Makaira nigricans). Mol. Mar. Biol. Biotechnol. 1, 206-214.

Fonteneau, A., Ariz J., Delgado A., Pallares P., Pianet R., 2005. A comparison of bigeye (Thunnus obesus) stocks and fisheries in teh Atlantic, Indian and Pacific oceans. Col. Vol. Sci. Pap. ICCAT 57, 41-66.

Fu, Y.-X., 1997. Statistical tests of neutrality of mutations against population growth, hitchhiking and background selection. Genetics 147, 915-925.

Graves, J.E., McDowell J.R., 1995. Inter-ocean genetic divergence of istiophorid billfishes. Mar. Biol. 122, 193-203.

Graves, J.E., McDowell J.R., 2003. Population structure of the world's billfishes: a genetic perspective. Mar. Freshwater Res. 54, 1-11.

Grewe, P.M., Hampton J., 1998. An assessment of bigeye (Thunnus obesus) population structure in the Pacific Ocean, based on mitochondrial DNA and DNA microsatellite analysis. SOEST 98-05, JIMAR Contribution 98-320.,

Guo, S., Thompson E., 1992. Performing the exact test of Hardy-Weinberg proportion for multiple alleles. Biometrics 48, 361-372.

Harpending, R.C., 1994. Signature of ancient population groth in a low-resolution mitochondrial DNA mismtach distribution. Hum. Biol. 66, 591-600.

Hudson, R.R., 2000. A new statistic of detecting genetic differentiation. Genetics $155,2001-2014$.

Jackson, J.B., Kirby M.X., Berger W.H., Bjorndal K.A., Botsford L.W., Bourque B.J., Bradbury R.H., Cooke R., Erlandson J., Estes J.A., Hughes T.P., Kidwell S., Lange C.B., Lenihan H.S., Pandolfi J.M., Peterson C.H., Steneck R.S., Tegner M.J., Warner R.R., 2001. Historical overfishing and the recent collapse of coastal ecosystems. Science 293, 629-37. 
Lecomte, F., Grant W.S., Dodson J.J., Rodriguez-Sanchez R., Bowen B.W., 2004. Living with uncertainty: genetic imprints of climate shifts in East Pacific anchovy (Engraulis mordax) and sardine (Sardinops sagax). Mol Ecol 13, 2169-82.

McMillan, W.O., Palumbi S.R., 1997. Rapid rate of control-region evolution in Pacific butterflyfishes (Chaetodontidae). J. Mol. Evol. 45, 473-484.

Miyabe, N., Takeuchi Y., Okamoto H., Restrepo V., 2005. A new attempt of Atlantic bigeye tuna (Thunnus obesus) stock assessment by statistical integrated model (Multifan-CL). Col. Vol. Sci. Pap. ICCAT 57, 177-200.

Nei, M., 1987. Molecular evolutionary genetics. Columbia University Press, New York.

Ostellari, L., Bargelloni L., Penzo E., Patarnello P., Patarnello T., 1996. Optimization of single-strand confromation polymorphism and sequence analysis of the mitochondrial control region in Pagellus bogaraveo (Sparidae, Teleostei): rationalized tools in fish population biology. Anim. Genet. 27, 423-427.

Pallares, P., Pereira J., Miyabe N., Fonteneau A., 1998. Atlantic bigeye tuna: overview of present knowledge (November 1996). In: Deriso, RB, Bayliff, wH, Webb, NJ (Eds.), Proceeding of the first world meeting on bigeye tuna. IATTC (InterAmerican Tropical Tuna Commission), La Jolla, pp. 20-80.

Palumbi, S.R., 1994. Genetic divergence, reproductive isolation, and marine speciation. Ann. Rev. Ecol. Syst. 25, 547-572.

Pauly, D., Christensen V., Guénette S., Pitceher T.J., Rashid Sumaila U., Walters C.J., Watson R., Zeller D., 2002. Towards sustainability in world fisheries. Nature $418,689-695$.

Peeters, F.J.C., Acheson R., Brummer G.-J.A., de Ruijter W.P.M., Schneider R.R., Ganssen G.M., Ufkes E., Kroon D., 2004. Vigorous exchange between the 
Indian and Atlantic oceans at the end of the past five glacial periods. Nature 430, 661-665.

Pereira, J., 1987. Sexual maturity and sex ratio of big eye tun caught in teh Azores. ICCAT Col. Vol. Sci. Pap. 26, 168-173.

Posada, D., Crandall K.A., 1998. Modeltest: testing the model of DNA substitution. Bioinformatics 14, 817-818.

Ramos-Onsins, S.E., Rozas J., 2002. Statistical properties of new neutrality tests against population growth. Mol. Biol. Evol. 19, 2092-2100.

Reeb, C.A., Arcangeli L., Block B.A., 2000. Structure and migration corridors in Pacific populations of the swordfish Xiphius gladius, as inferred through analyses of mitochondrial DNA. Mar. Biol. 136, 1123-1131.

Rice, W.R., 1989. Analyzing tables of statistical tests. Evolution 43, 223-225.

Rogers, A.R., Harpending H., 1992. Population growth makes waves in the distribution of pairwise genetic differences. Mol Biol Evol 9, 552-569.

Rozas, J., Sánchez-DelBarrio J.C., Messeguer X., Rozas R., 2003. DnaSP, DNA polymorphism analysis by the coalescent and other methods. Bioinformatics 19, 2496-2497.

Saitou, N., Nei M., 1987. The neighbor-joining method: a new method for reconstructing phylogenetic trees. Mol. Biol. Evol. 4, 406-425.

Schaefer, K.M., Fuller D.W., 2005. Conventional and archival tagging of bigeye tuna (Thunnus obesus) in the eastern equatorial Pacific Ocean. Col. Vol. Sci. Pap. ICCAT $57,67-84$.

Schneider, S., Excoffier L., 1999. Estimation of past demographic parameters from the distribution of pairwise differences when the mutation rates vary among sites: application to human mitochondrial DNA. Genetics 152, 1079-89. 
Schneider, S., Roessli D., Excoffier L., 2000. Arlequin ver 2.000: a software for population genetics data analysis. Genetics and Biometry Laboratory. University of Geneva, Geneva

Slatkin, M., Hudson R.R., 1991. Pairwise comparisons of mitochondrial DNA sequences in stable and exponentially growing populations. Genetics 129 , 555-62.

Swofford, D.L., 1998. PAUP*: Phylogenetic Analysis Using Parsimony (*and other methods), version 4.0. Sinauer Associates, Inc., Sunderland, MA, US.

Tajima, F., 1983. Evolutionary relationship of DNA sequences in finite populations. Genetics 105, 437-460.

Tajima, F., 1989. Statistical method for testing the neutral mutation hypothesis by DNA polymorphism. Genetics 123, 585-595.

Tamura, K., Nei M., 1993. Estimation of the number of nucleotide substitutions in the control region of mitochondrial DNA in humans and chimpanzees. Mol. Biol. Evol. 10, 512-526.

Viñas, J., Alvarado Bremer J., Pla C., 2004a. Phylogeography of the Atlantic bonito (Sarda sarda) in the northern Mediterranean: the combined effects of historical vicariance, population expansion, secondary invasion, and isolation by distance. Mol Phylogenet Evol 33, 32-42.

Viñas, J., Alvarado Bremer J.R., Pla C., 2004b. Inter-oceanic genetic differentiation among albacore (Thunnus alalunga) populations. Mar. Biol. 145, 225-232.

Weir, B.S., Cockerham C.C., 1984. Estimating F-statistics for the analysis of population structure. Evolution 38, 1358-1370.

Zardoya, R., Castilho R., Grande C., Favre-Krey L., Caetano S., Marcato S., Krey G., Patarnello T., 2004. Differential population structuring of two closely related fish species, the mackerel (Scomber scombrus) and the chub mackerel (Scomber japonicus), in the Mediterranean Sea. Mol Ecol 13, 1785-98. 
Table 1 Descriptive statistics for the studied T. obesus samples*

\begin{tabular}{ccccccccccc}
\hline Population & Location & Date & $n$ & $\mathrm{FL}($ mean $\pm \mathrm{SD})$ & No. Haplotypes & $S$ & $H_{d}$ & $k$ & $\pi$ \\
\hline Guinea & $8^{\circ} \mathrm{N} ; 24^{\circ} \mathrm{W}$ & May 01 & 50 & $43.6 \pm 2.3$ & 45 & 69 & $0.996 \pm 0.005$ & $19.0 \pm 8.6$ & $0.056 \pm 0.028$ & $15.4 \pm 4.6$ \\
Guinea2 & $4^{\circ}-5^{\circ} \mathrm{N} ; 1^{\circ} \mathrm{W}-1^{\circ} \mathrm{E}$ & 2003 & 45 & $57.5 \pm 12.7$ & 34 & 74 & $0.983 \pm 0.009$ & $19.0 \pm 8.7$ & $0.056 \pm 0.028$ & $16.9 \pm 5.1$ \\
Azores & $40^{\circ} \mathrm{N} ; 30^{\circ} \mathrm{W}$ & June 01 & 50 & $61.9 \pm 7.0$ & 48 & 80 & $0.998 \pm 0.004$ & $21.2 \pm 9.5$ & $0.063 \pm 0.031$ & $17.9 \pm 5.2$ \\
Canary & $28^{\circ} \mathrm{N} ; 18^{\circ} \mathrm{W}$ & August 01 & 33 & $76.85 \pm 11.5$ & 33 & 66 & $1.000 \pm 0.007$ & $18.5 \pm 8.4$ & $0.055 \pm 0.028$ & $16.3 \pm 5.2$ \\
Canary2 & $28^{\circ} \mathrm{N} ; 18^{\circ} \mathrm{W}$ & Mar-Jul 03 & 28 & $64.4 \pm 10.4$ & 26 & 59 & $0.995 \pm 0.011$ & $20.0 \pm 9.1$ & $0.059 \pm 0.030$ & $15.2 \pm 5.1$ \\
Canada & $40^{\circ} \mathrm{N} ; 63^{\circ} \mathrm{W}$ & Nov-Dec 01 & 42 & $113.0 \pm 8.6$ & 39 & 73 & $0.996 \pm 0.006$ & $19.5 \pm 8.8$ & $0.058 \pm 0.030$ & $17.0 \pm 5.2$ \\
Indian & $0^{\circ}-3^{\circ} \mathrm{N} ; 45^{\circ}-56^{\circ} \mathrm{E}$ & July 02 & 47 & not avaliable & 44 & 74 & $0.997 \pm 0.005$ & $14.5 \pm 6.6$ & $0.043 \pm 0.022$ & $16.7 \pm 5.0$ \\
Pacific & $8^{\circ} \mathrm{S} ; 109^{\circ} \mathrm{W}$ & Nov 03 & 36 & $80.4 \pm 3.5$ & 36 & 68 & $1.000 \pm 0.006$ & $13.1 \pm 6.0$ & $0.039 \pm 0.020$ & $16.4 \pm 5.2$ \\
\hline
\end{tabular}

${ }^{\star} n=$ sample size, $\mathrm{FL}=$ lower jaw fork length, $S=$ number of polymorphic sites, $H_{d}=$ gene diversity (Nei 1987), $k=$ mean pairwise nucleotide differences (Tajima 1993), $\pi=$ nucleotide diversity (Nei 1987), $\theta=$ expected heterozygosity per site (Watterson 1975) 
Table 2

Descriptive statistics of T. obesus phylogroups (clades I/ II) based on mitochondrial control region sequence data*

\begin{tabular}{ccccccc}
\hline Population & $\mathrm{n}$ & No. Haplotypes & $\mathrm{S}$ & $H_{d}$ & $k$ & $\pi$ \\
\hline Guinea & $13 / 35$ & $11 / 32$ & $38 / 38$ & $0.97 \pm 0.04 / 0.99 \pm 0.01$ & $13.2 \pm 6.3 / 9.3 \pm 4.4$ & $0.039 \pm 0.021 / 0.028 \pm 0.014$ \\
Azores & $17 / 30$ & $16 / 29$ & $47 / 55$ & $0.99 \pm 0.02 / 1.00 \pm 0.01$ & $12.1 \pm 5.8 / 11.9 \pm 5.6$ & $0.036 \pm 0.019 / 0.035 \pm 0.018$ \\
Canary & $5 / 27$ & $5 / 27$ & $21 / 46$ & $1.00 \pm 0.13 / 1.00 \pm 0.01$ & $10.5 \pm 5.8 / 11.7 \pm 5.5$ & $0.031 \pm 0.020 / 0.034 \pm 0.018$ \\
Canada & $8 / 32$ & $8 / 29$ & $34 / 51$ & $1.00 \pm 0.06 / 0.99 \pm 0.01$ & $12.7 \pm 6.4 / 11.4 \pm 5.3$ & $0.037 \pm 0.022 / 0.034 \pm 0.017$ \\
Indian & $37 / 0$ & $35 / 0$ & $61 / 0$ & $1.00 \pm 0.01 /-$ & $11.2 \pm 5.2 /-$ & $0.033 \pm 0.017 /-$ \\
Pacific & $27 / 0$ & $27 / 0$ & $55 / 0$ & $1.00 \pm 0.01 /-$ & $10.6 \pm 5.0 /-$ & $0.031 \pm 0.016 /-$ \\
\hline
\end{tabular}

${ }^{\star} n=$ sample size, $S=$ number of polymorphic sites, $H_{d}=$ gene diversity (Nei 1987), $k=$ mean pairwise nucleotide differences

(Tajima 1993), $\pi=$ nucleotide diversity (Nei 1987) 
Table 3

Genetic structuring of $T$. obesus populations based on mitochondrial control region sequence data

\begin{tabular}{|c|c|c|c|c|}
\hline \multicolumn{5}{|c|}{ Observed partition } \\
\hline Structure tested & Variance & $\%$ total & $\Phi$ Statistics & $P$ \\
\hline \multicolumn{5}{|c|}{ 1. One gene pool (Guinea, Canary, Azores, Canada, Indian, Pacific) } \\
\hline Among populations & 2.55 & 22.25 & \multirow{2}{*}{$\Phi_{S T}=0.22$} & \multirow{2}{*}{$<0.01$} \\
\hline Within populations & 8.90 & 77,75 & & \\
\hline \multicolumn{5}{|c|}{ 2. One gene pool Clade I (Guinea, Canary, Azores, Canada, Indian, Pacific) } \\
\hline Among populations & 0.12 & 2.10 & \multirow[t]{3}{*}{$\Phi_{S T}=0.02$} & \multirow[t]{3}{*}{0.01} \\
\hline Within populations & 5.76 & 97,9 & & \\
\hline \multicolumn{3}{|c|}{ 3. One gene pool Clade II (Guinea, Canary, Azores, Canada) } & & \\
\hline Among populations & $-0,03$ & -0.50 & \multirow{2}{*}{$\Phi_{S T}=-0.05$} & \multirow[t]{2}{*}{0.72} \\
\hline Within populations & 5.51 & 100.50 & & \\
\hline \multicolumn{5}{|c|}{ 4. Two gene pools Clade I (Guinea, Canary, Azores, Canada) (Indian, Pacific) } \\
\hline Among groups & -0.02 & -0.28 & $\Phi_{C T}=-0.01$ & 0.40 \\
\hline Within groups & 0.13 & 2.27 & $\Phi_{S C}=0.02$ & 0.06 \\
\hline Within populations & 5.76 & 98.01 & $\Phi s T=0.02$ & 0.01 \\
\hline
\end{tabular}


Table 4

Matrix of pairwise $\Phi_{\text {ST }}$ (below diagonal) and associated $P$ (above diagonal) values among $T$. obesus samples based on mitochondrial control region sequence data

\begin{tabular}{lcccccc}
\hline & Guinea & Azores & Canary & Canada & Indian & Pacific \\
\hline Guinea & - & 0.28 & 0.25 & 0.34 & 0 & 0 \\
Azores & 0.002 & - & 0.04 & 0.08 & 0 & 0 \\
Canary & 0.005 & 0.033 & - & 0.95 & 0 & 0 \\
Canada & 0.001 & 0.018 & -0.015 & - & 0 & 0 \\
Indian & $0.350^{*}$ & $0.267^{*}$ & $0.436^{*}$ & $0.398^{*}$ & - & 0.76 \\
Pacific & $0.356^{*}$ & $0.273^{*}$ & $0.448^{*}$ & $0.407^{*}$ & -0.006 & - \\
\hline
\end{tabular}

* significant at $p<0.005$ (after Bonferroni correction) 
Table 5

Matrix of pairwise $\Phi_{S T}$ (below diagonal) and associated $P$ (above diagonal) values among $T$. obesus phylogroups (Clade I/ Clade II) based on mitochondrial control region sequence data

\begin{tabular}{lcccccc} 
& Guinea & Azores & Canary & Canada & Indian & Pacific \\
\hline Guinea & - & $0.07 / 0.76$ & $0.22 / 0.27$ & $0.02 / 0.35$ & $0.01 /-$ & $0.01 /-$ \\
Azores & $0.040 /-0.009$ & - & $0.20 / 0.72$ & $0.26 / 0.51$ & $0.66 /-$ & $0.52 /-$ \\
Canary & $0.034 / 0.005$ & $0.029 /-0.010$ & - & $0.26 / 0.95$ & $0.38 /-$ & $0.45 /-$ \\
Canada & $0.091 / 0.002$ & $0.015 /-0.003$ & $0.023 /-0.017$ & - & $0.04 /-$ & $0.09 /-$ \\
Indian & $0.054 * /-$ & $-0.007 /-$ & $0.007 /-$ & $0.042 /-$ & - & $0.68 /-$ \\
Pacific & $0.069 * /-$ & $-0.002 /-$ & $-0.001 /-$ & $0.031 /-$ & $-0.005 /-$ & - \\
\hline
\end{tabular}

*significant values at $p<0.005$ (after Bonferroni correction) 
Table 6

Statistical tests of neutrality, and demographic parameters estimates for $T$. obesus entire mitochondrial control region data set, and phylogroups (Clades I/ II)

All samples

Clade I

Clade II

Goodness of fit tests

Tajima $D$

$-0.65$

$-1.34^{*}$

$-1.25$

Fu $F_{s}$

$-320.99 *$

$-124.96^{\star}$

$-126.04^{\star}$

Demographic parameters

Hri

$\begin{array}{lll}0.0021 & 0.0052 & 0.0029\end{array}$

$S S D$

$0.0134^{*}$

0.0008

0.0003

$\mathrm{S}$

118

87

79

$\theta_{0}$

16.358

0

2.197

$\theta_{1}$

3025

3795

107

$\frac{\tau}{\text { * significant at } p<0.05}$ 
Table 7

Gene-flow estimates for $T$. Obesus based on mitochondrial control region sequence data

\begin{tabular}{|c|c|c|c|c|c|c|c|c|}
\hline \multirow[t]{2}{*}{ Population } & Theta & $\mathrm{N}_{\mathrm{f}}^{*}$ & $2 \mathrm{~N}_{\mathrm{f}} \mathrm{m}^{\dagger}$ & & & & & \\
\hline & {$\left[2 \mathrm{~N}_{\mathrm{f}} \mathrm{\mu}\right]$} & & 1 & 2 & 3 & 4 & 5 & 6 \\
\hline 1 Guinea & 0.11 & $5.5 \times 10^{5}$ & & 366 & 368 & 96 & 15 & 14 \\
\hline 2 Azores & 3.75 & $1.9 \times 10^{7}$ & 458 & & 498 & 215 & 33 & 14 \\
\hline 3 Canary & 0.15 & $7.5 \times 10^{5}$ & 34 & 16 & & 4 & 7 & 29 \\
\hline 4 Canada & 0.86 & $4.3 \times 10^{6}$ & 40 & 757 & 92 & & 0 & 11 \\
\hline 5 Indian & 0.48 & $2.4 \times 10^{6}$ & 0 & 0 & 0 & 0 & & 3699 \\
\hline 6 Pacific & 0.33 & $1.6 \times 10^{6}$ & 2 & 0 & 1 & 1 & 628 & \\
\hline
\end{tabular}

All values within bounds of $95 \%$ confidence limit

*Using a $\mu=1.1 \times 10^{-7}$ per site per year (MacMillan \& Palumbi 1997)

${ }^{\dagger}$ columns are donor populations whereas rows are receiving populations 


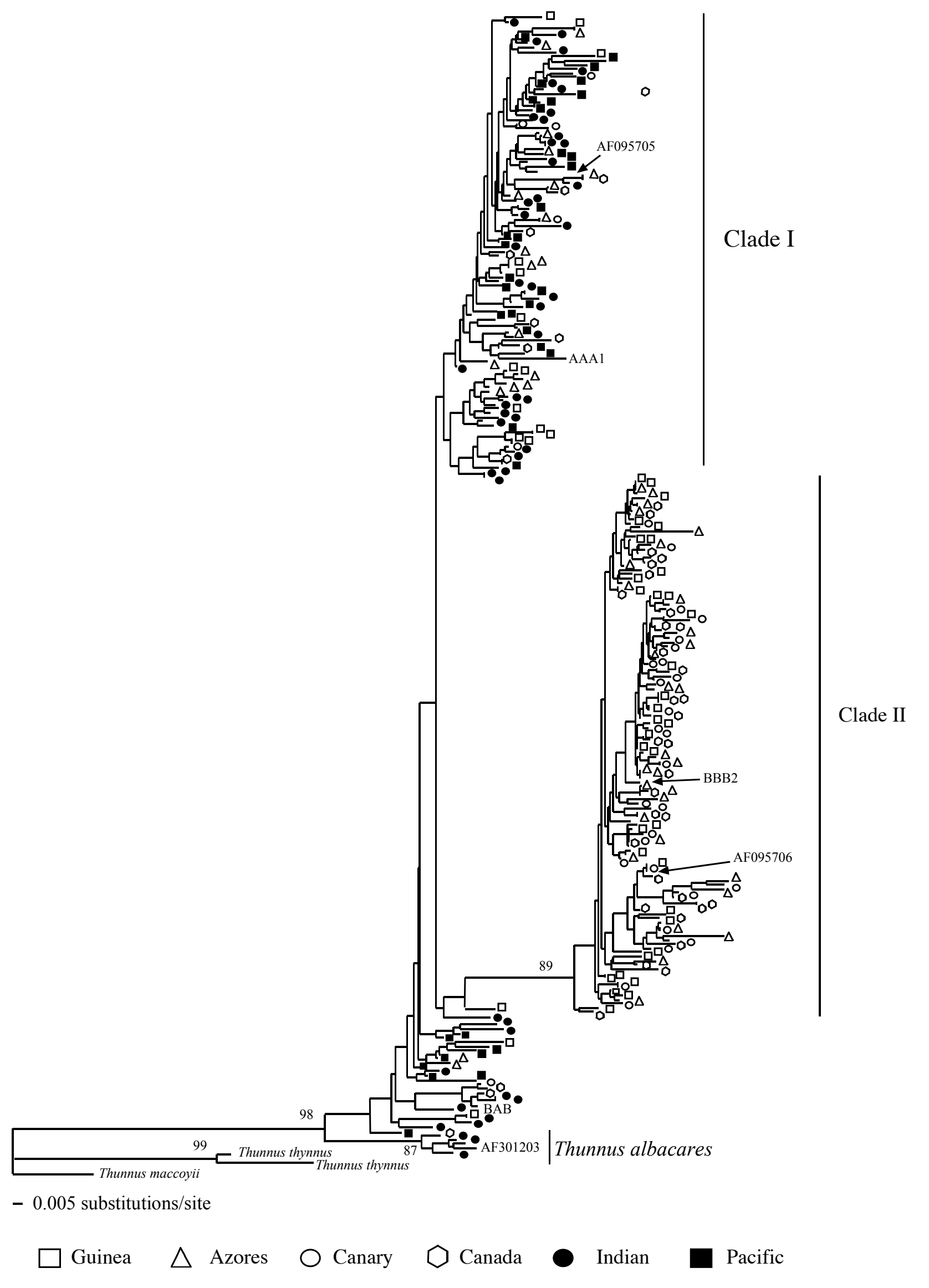




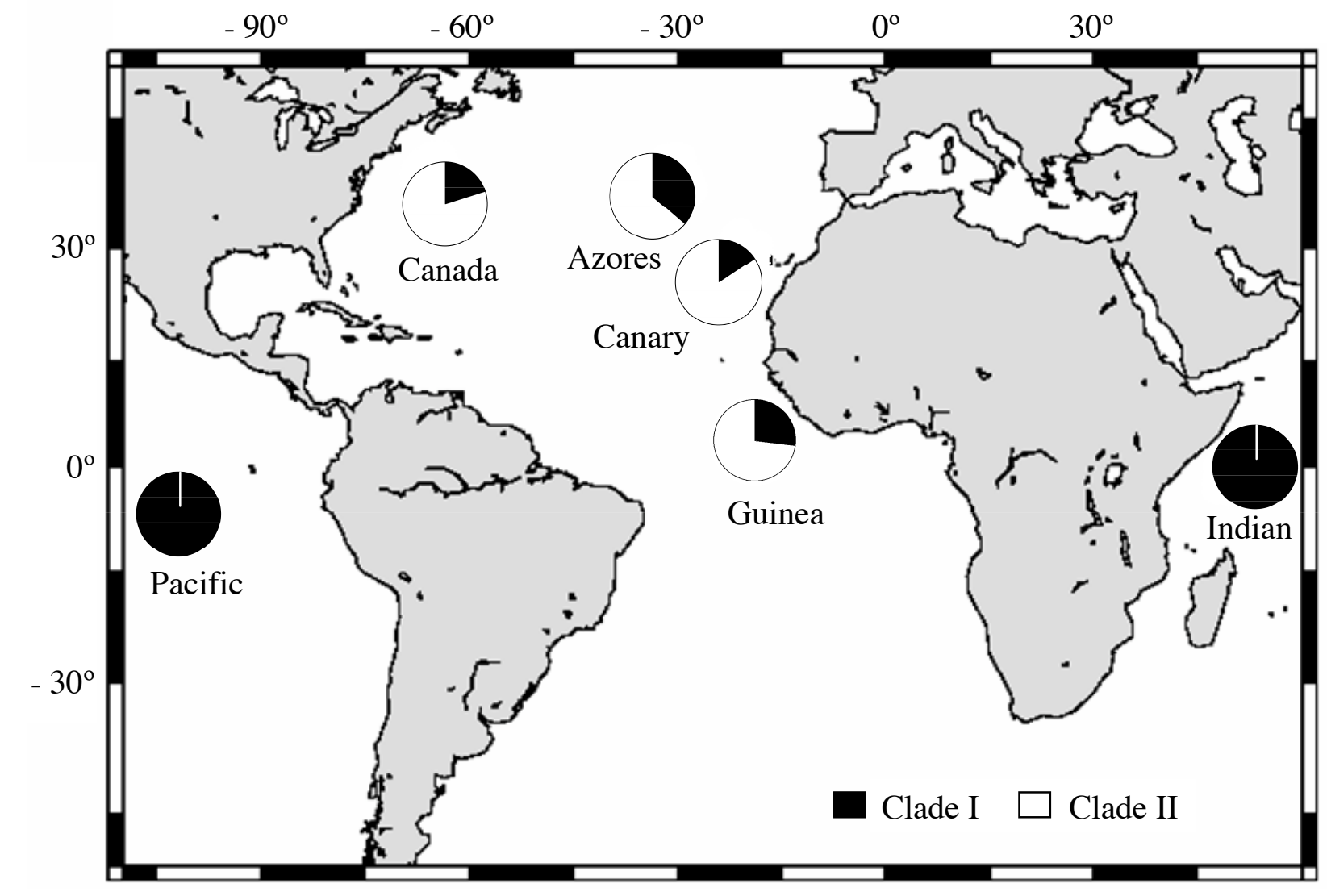




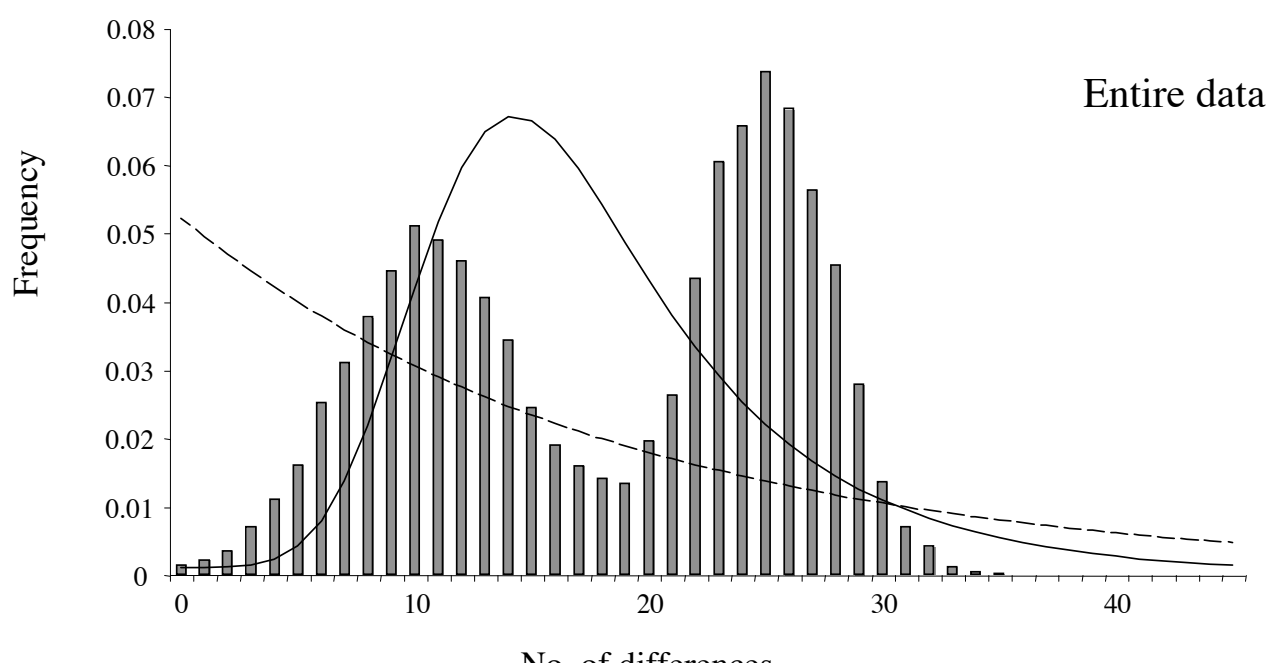

No. of differences
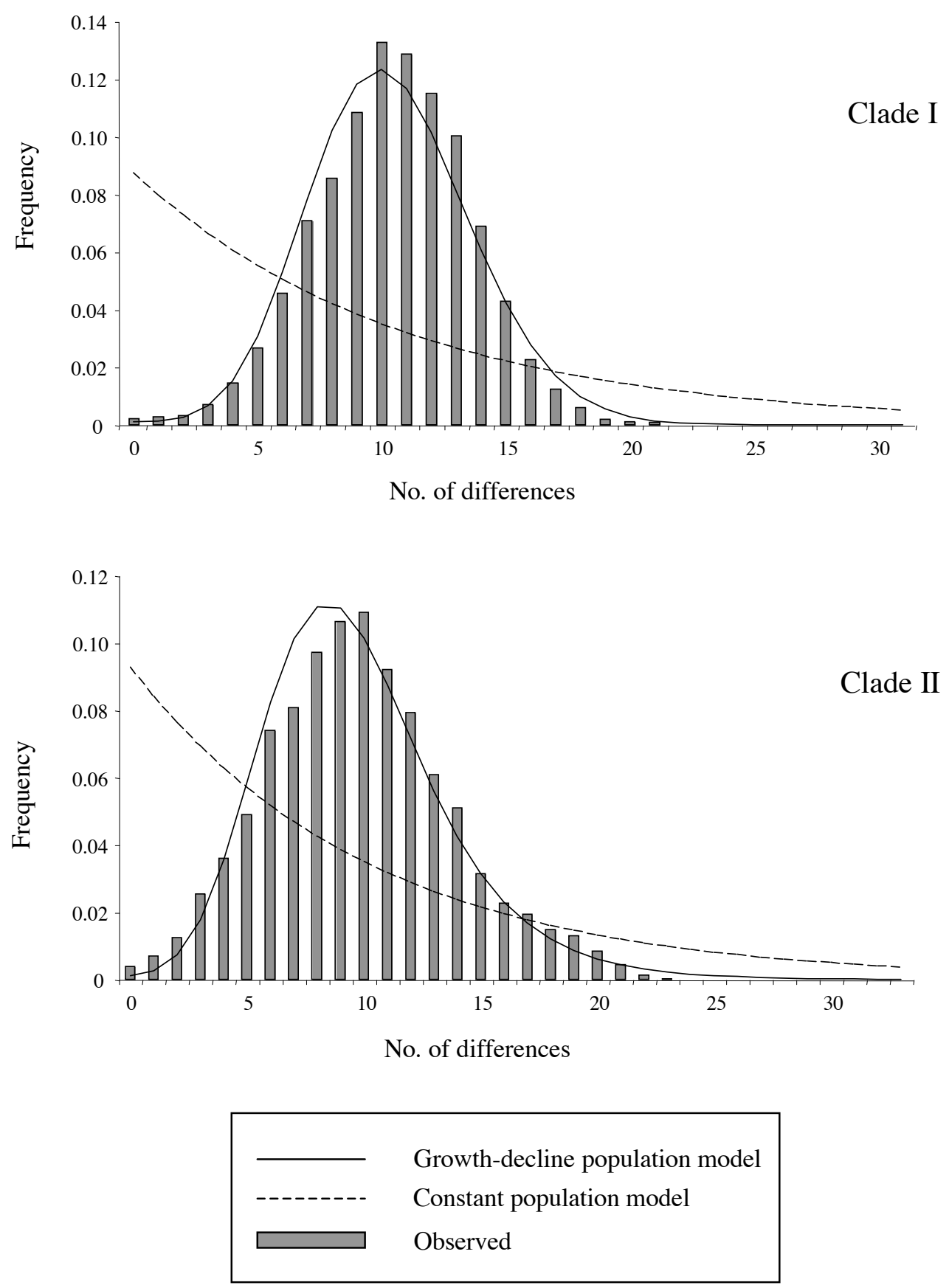